\title{
Educational Federalism and the Quality Effects of Tuition Fees
}

\author{
Alexander Kemnitz* \\ University of Mannheim \\ Department of Economics \\ D-68131 Mannheim
}

September 22, 2005

\begin{abstract}
This paper investigates how the abolishment of a ban on tuition fees affects the quality of higher education with centralized and decentralized decision making. It is shown that tuition fees fully crowd public funds under centralization and quality of university education does not improve. However, with decentralized decisions total higher education spending increases in the tuition level. Therefore, decentralization can lead to a higher quality of university education than centralization although the opposite holds when funding is restricted to be public.
\end{abstract}

JEL classifications: H77, I22, D78

Keywords: Higher Education, Federalism, Tuition Fees.

*Tel: +49-621-1811798. Fax: +49-621-1811794. e-mail: kemnitz@econ.uni-mannheim.de. I would like to thank Eckhard Janeba for helpful comments and suggestions. 


\section{Introduction}

Does the introduction of tuition fees improve the quality of higher education? Numerous voices throughout Europe support this view, stating that fees are heavily needed to supplement public educational expenditures in order to bring funding back to internationally adequate levels (Barr, 2005, Chapter 4; European Commission, 2005; HRK, 2005). However, critics argue that enhanced access to private financing sources would actuate a withdrawal of public funding, which would result in a poor or even zero net effect on total educational spending. ${ }^{1}$ This fear is fuelled by recent experiences after the introduction of tuition fees in the UK and Australia, summarized by Barr (2004, p. 342):

If fees are set by government, rising fee income can be offset by falling taxpayer contributions. ... Australia is a graphic example: government introduced centrally set fees 1989 to address a funding crisis; by 2000, the system was back in crisis. Equally, the introduction of fees in the UK did not net any extra money.

This paper develops a simple model of higher education finance to address the question whether the option to implement tuition fees improves the quality of university education and to what extent crowding out of public funds occurs. This question is of particular importance for the debate in Germany, where the ban on tuition fees was recently abandoned by the Federal Constitutional Court and, similar to the abovementioned countries, fees are planned to be introduced gradually at levels determined by the political process. As a result, higher education funding rests on both public and private sources, an aspect typically neglected in models of university finance reform focussing only on the polar alternatives of pure public vs. private expenditures (Garcia-Peñalosa and Wälde, 2000; Wildasin, 2000; Büttner and Schwager, 2004). ${ }^{2}$

In many countries, the dispute on university reform goes hand in hand with a discussion on the proper allocation of educational competencies, in particular between federal and regional levels. From a theoretical perspective, arguments in favor of decentralization are weak due to a variety of interregional spill-overs, including the comparability

1 Of course, the discussion on the interrelation between financing sources and quality is just one aspect in the voluminous tuition fee debate. Other topics figuring prominently in public discussion include lifetime redistribution, see Kupferschmidt and Wigger (2005) for a survey, and social selectivity due to financial constraints (De Fraja, 2001)

2 Since the level of the fee is controlled by the government, our notion of "private funding" should not be confused with private choice on educational quality. 
of degrees (Somanathan, 1998), ability sorting (Fernandez and Rogerson, 1996) or tax competition for mobile graduates (Wildasin, 2000; Andersson and Konrad, 2003). Therefore, we investigate how the possibility to charge tuition fees affects educational expenditures for both centralized and decentralized decision making. Again, this has some relevance for Germany because, unlike to Australia and the UK, fees are determined at the federal state level.

We find that the degree of decentralization matters for the effect of the availability of tuition fees on university quality. When funding is determined by central government, fees substitute public funds extensively without improving the quality of university education. However, with regional decision making, per capita spending on higher education increases when tuition fees are charged. These differences originate in the higher elasticity of student enrolment with respect to fee increases at the regional than at the federal level. The possibility to study in the other region limits the ability of the regional governments to shift the financing burden of higher education to students.

This result has important implications for the assessment of educational federalism. We argue that the option to use tuition fees can provide an argument in favor of a decentralization of educational decisions. Our analysis identifies situations where centralization leads to higher quality than decentralization when funding is restricted to be only public, but decentralization performs better when tuition fees are admitted. This finding is rooted in a distortion of the incentives to support university education by the political process. Not attending university himself, the decisive voter recognizes only the indirect benefits of higher education and neglects the positive direct effects on students. This renders spending under centralization inefficient and opens up the possibility of a better provision by decentralization even though regions are symmetric. Hence, our mechanism differs significantly from Besley and Coate (2003), where a superiority of decentralized systems originates in the heterogeneity of individual preferences.

The paper is organized as follows. Section 2 sets up the basic ingredients of the model. Section 3 derives and compares spending levels under centralized and decentralized decision making when tuition fees are banned. In section 4, this ban is abolished. Section 5 offers some concluding remarks. 


\section{The Model}

Consider a federation formed by two ex ante identical regions $i \in\{A, B\}$. In both regions, competitive firms employ labor to produce the same output good by a constantreturns-to-scale technology. International capital mobility pegs the interest rate at the level $r$ for both individuals and firms. Hence, the wage per efficiency unit of labor $w$ is constant as well.

We focus on two subsequent periods $t=1,2$ in this economy. In period 1 , there are two generations, called the parents and the children. In each region, a mass of children which we normalize to unity is born by $P$ parents. In period 2 , however, only the children are alive. ${ }^{3}$ Children are heterogeneous in terms of the ability to benefit from education, $a$, and the costs of moving into the other region in period 1 and 2, denoted by $\mu_{t}, t=1,2 .{ }^{4}$ To simplify matters, parents are assume to be immobile.

At the beginning of each period, the children are informed about their individual realization of the respective mobility cost. These costs reflect not only immediate transportation costs, but also non-monetary aspects of leaving a familiar environment, which may be considered positive by some individuals. Therefore, we allow for non-positive values of total mobility cost. For the sake of concreteness, costs are uncorrelated between periods and $\mu_{t}$ follows a uniform distribution in the interval: $\left[\underline{\mu}_{t}, \bar{\mu}_{t}\right]$ with $\underline{\mu}_{t} \leq 0$. Hence, the probability of facing a migration cost $\mu_{t}$ is $1 /\left(\bar{\mu}_{t}-\underline{\mu}_{t}\right)$.

In addition to residence, children decide in period 1 whether to take up a study. Doing so augments the effective supply of labor in period 2 to: ${ }^{5}$

$$
1+a h(e)
$$

where $a$ reflects the ability to benefit from higher education and $h(e)$ is a human capital production function with the usual properties $\left(h^{\prime}>0, h^{\prime \prime}<0, h^{\prime}(0)=\infty\right.$ and $\left.h(0)=0\right)$. Human capital depends on total higher education expenditures or quality $e=g+f$, which consist of both public funds $g$ and tuition fees $f$. Taking into account income taxation at the rate $\tau$ and tuition cost gives lifetime net income:

3 Setting up a fully fledged overlapping generations model would complicate notation without affecting the results.

4 Moving beyond the borders of the federation is ruled out to fix ideas.

5 For simplicity, we abstract from uncertainty about the success of the study. Hence, all current students are future graduates in the model. 


$$
I_{H}=\frac{(1-\tau)(1+a h(e)) w}{1+r}-f .
$$

Like Keen and Marchand (1997) and Poutvaara (2004), we treat the income tax rate $\tau$ as fixed throughout the paper. Hence, the paper focusses on the effect of mobility on educational and not on tax competition. We discuss this assumption in the conclusions section.

Children not attending university supply one efficiency unit of labor in both periods. This leads to net lifetime earnings:

$$
I_{L}=(1-\tau) w\left(\frac{2+r}{1+r}\right)
$$

The ability distribution is bimodal. In each region, the number $A$ of children is born with a high ability to benefit from university education $(a=1)$, whereas the rest $(1-A)$ has no such talent $(a=0)$. Hence, the total number of talented individuals is $2 A$.

The decision to study results from a comparison of lifetime incomes. While untalented individuals abstain from studying due to the opportunity cost, the talented attend university only if:

$$
(1-\tau) w\left(\frac{h(e)}{1+r}-1\right) \geq f
$$

that is, the increase in net earnings at least compensates for tuition cost. Put differently, the number of students $S$ is only positive, if the quality of education exceeds a minimum level $\bar{e}_{0}(f)$, for which $(1)$ holds with equality:

$$
S=\left\{\begin{array}{rl}
A & : \quad e \geq \bar{e}_{0}(f) \\
0 & : \quad e<\bar{e}_{0}(f)
\end{array} .\right.
$$

Obviously, the minimum quality increases in the tuition fee level: $\bar{e}_{0}^{\prime}(f)=(1+r) /((1-$ $\left.\tau) h^{\prime}\left(\bar{e}_{0}\right)\right)$ with $\bar{e}_{0}(0)$ given by $h\left(\bar{e}_{0}(0)\right)=1+r$.

Our welfare criterion for the comparison of different funding levels is aggregate production by the young generation:

$$
2 S \frac{1+h(e)}{1+r} w+2(1-S) w \frac{2+r}{1+r}-2 S e .
$$

This expression is maximized either by having no higher education at all $(e=S=0)$ or all talented going to university and receiving the same quality $e^{*}$, characterized by: 


$$
h^{\prime}\left(e^{*}\right) w=1+r
$$

This condition has the simple interpretation that the marginal returns to investment in human and physical capital must coincide. To make things interesting, we assume that the resulting aggregate surplus created is higher than if no-one attended university:

$$
\begin{aligned}
2 A \frac{1+h\left(e^{*}\right)}{1+r} w+2(1-A) w \frac{2+r}{1+r}-2 A e^{*} & >2 w \frac{2+r}{1+r} \\
\left(h\left(e^{*}\right)-(1+r)\right) w & >e^{*}(1+r) .
\end{aligned}
$$

Hence, higher education is socially productive. ${ }^{6}$ Because aggregate production is concave in $e$, social productivity obtains for all $e \in(0, \bar{e}]$ where $\bar{e}>e^{*}$ is implicitly defined by $(h(\bar{e})-(1+r)) w=\bar{e}(1+r)$.

\section{Public Funding of Higher Education}

This section investigates spending on higher education when all funds are public, that is, tuition fees are not allowed: $f=0$. The level of public spending results from the political process.

Throughout the industrialized world, (potential) students make up for a minor part of the constituency. As a consequence, public support for higher education depends heavily on the existence of some indirect beneficial effects for the general public. While some approaches focus on externalities (Creedy and Francois, 1990) or factor complementarities (Poutvaara and Kanniainen, 2000), we conceive public higher education as the result of intergenerational redistribution.

We devise of a situation where political process is dominated by the parents who dispose of two policy instruments in period $1 .^{7}$ First, current tax revenues can be spent either on a demogrant transfer $b$ to the parents or on higher education $g$. Second, the parents

6 A comparison of (1) and (4) highlights the imperfect congruence between efficiency in higher education and university attendance. For pure public funding, the talented go to university also for inefficiently low qualities $e \geq \bar{e}_{0}(0)$. With pure private tuition, this is only true if the fee is smaller than $(1-\tau) e^{*}$.

7 There are two obvious ways to justify this assumption. First, one could assume a higher political power of the old in the sense of a gerontocracy. Second, one could posit equal political influence, but $P>1$, such that the decisive voter is a parent. In either case, the political process leads to results similar to Leviathan-type governments (Andersson and Konrad, 2003). 
can issue government debt $D$ to be repaid by the children in period 2, enabling parents to convert future tax payments into period 1 consumption. Hence, the incentive for public spending on higher education originates in a widening of the future tax base. ${ }^{8}$ Since the transfer is uniform, earnings heterogeneity among parents plays no role in political decisions and is therefore not modelled explicitly.

\subsection{Centralization}

Consider first a setting where education and debt policies are set by a central government. Then, the government budget constraints in both periods are:

$$
\begin{aligned}
T_{1}+D & =2 P \cdot b+2 S \cdot g \\
T_{2} & =D(1+r)
\end{aligned}
$$

where period 1 tax revenues results from those children not attending university:

$$
T_{1}=2(1-S) \tau w
$$

whereas all children pay a proportional income tax in the next period: ${ }^{9}$

$$
T_{2}=2 \tau w[S(1+h(g))+(1-S)]
$$

Consolidating the budget constraints gives the net transfer to parents as a function of educational expenditures in period 1 :

$$
b(g)=\frac{1}{2 P}\left[T_{1}+\frac{T_{2}}{1+r}-2 S g\right] .
$$

Expenditures on public higher education are chosen in order to maximize (8) subject to (2). Due to the concavity of the human capital production function, the benefit is concave in $g$ attaining the level $2(1-S) \tau w(2+r) /(1+r)$ for both $g=0$ and some positive $\tilde{g}<\bar{e}$. Let $\bar{g}^{C}$ denote the solution to the respective first order condition:

8 A similar argument could be developed in terms of pay-as-you-go pension benefits which are financed by wage contributions. See e.g. Soares (2005) for a respective comparison between decentralized and centralized education funding.

9 Additional period 1 tax payments by parents could be introduced without affecting the results. 


$$
h^{\prime}\left(\bar{g}^{C}\right) w=\frac{1+r}{\tau} .
$$

Then, centralized higher education spending amounts to

$$
\left\{\begin{aligned}
\bar{g}^{C} & : \quad \bar{e}_{0}(0) \leq \bar{g}^{C} \\
\bar{e}_{0}(0) & : \quad \bar{g}^{C}<\bar{e}_{0}(0)<\tilde{g} \\
0 & : \quad \bar{e}_{0}(0) \geq \tilde{g}
\end{aligned}\right.
$$

Proposition 1. For all $\tau<1$, centralized pure public higher education is underfunded.

Proof. Inefficiency holds whenever $\bar{e}_{0} \geq \bar{g}^{C}$ because $e^{*}>\bar{e}_{0}(0)>0$ from (1) and (4). For $\bar{g}^{C}>\bar{e}_{0}, \frac{d \bar{g}^{C}}{d \tau}>0$ with $\bar{g}^{C}=e^{*}$ iff $\tau=1$.

The parental motive to provide higher education originates in the appropriation of period 2 tax revenues through government debt. However, aggregate output increases by more than the tax revenue whenever the tax rate is not confiscatory. This renders the incentives to finance university education inferior. ${ }^{10}$

Both Bevia and Iturbe-Ormaexte (2002) and Wigger and von Weizsäcker (2001) develop a similar argument for public support of higher education. In Bevia and IturbeOrmaexte (2002), altruistic parents are willing to forego current tax revenue in order to finance higher education which fosters future redistribution among the offspring via a progressive income tax. In our model, selfish parents redistribute resources to themselves. Wigger and von Weizsäcker (2001) assume that the government maximizes a "tax dividend" in the form of future student earnings. However, they do not address the problem of underfunding caused by an imperfect appropriation of investment returns.

Without loss of substantial insights, the subsequent analysis concentrates on the case where the student participation constraint is not binding in the centralized equilibrium, that is $\bar{g}^{C} \geq \bar{e}_{0}$.

The conventional method of financing higher education by general taxation has often been attacked on grounds of regressive redistribution (Garcia-Peñalosa and Wälde, 2000). This obtains also in our model as the ratio between academic and non-academic lifetime income among children:

$$
\frac{1+h(g)}{2+r}
$$

10 To simplify the analysis, we have omitted any personal effort cost of attending university. Obviously, the presence of such a cost would destroy the incentives for university education for $\tau=1$ such that centralized pure public education would never be efficient. 
increases monotonously in $g$. This is due to the fact that parents are not interested in intra-, but intergenerational redistribution, which is promoted by fostering the earnings of the talented children.

\subsection{Decentralization}

Consider now a situation where policies are chosen autonomously at regional levels. Similar to the centralized case, parents want to maximize the net transfer to their region:

$$
b^{i}\left(g^{i}\right)=\frac{1}{P}\left[T_{1}^{i}+\frac{T_{2}^{i}}{1+r}-S^{i} g^{i}\right],
$$

where $i$ is the regional index. However, the existence of both interregional mobility and a fiscal equalization scheme modifies tax revenues and costs in three distinctive ways, compared to the above section.

First, mobility in period 2 implies that not all graduates of a region will pay income taxes in that region. Graduate earnings being the same across regions due to the uniform income tax rate, all households with negative mobility costs move to the other region at the beginning of period 2. As a consequence, each region collects taxes from its period-1 residents with positive old age mobility cost $\mu_{2}$ and all former residents in the other region with negative $\mu_{2}$. Letting $S^{i}$ denote the number of graduates in $i$, this region collects taxes in amount of:

$$
T C_{2}^{i}=\frac{\bar{\mu}_{2}}{\bar{\mu}_{2}-\underline{\mu}_{2}} \tau\left(1+h\left(g^{i}\right)\right) w S^{i}+\frac{-\underline{\mu}_{2}}{\bar{\mu}_{2}-\underline{\mu}_{2}} \tau\left(1+h\left(g^{j}\right)\right) w S^{j}+\tau w(1-S),
$$

where $j \neq i$ and the last term is due to the fact that the number of non-academics with negative $\mu_{2}$ is the same in both regions.

Second, fiscal equalization drives a wedge between the taxes collected and the taxes received by each region. Let $\delta \in[0,1]$ be the fraction of taxes that remain in the region of collection, revenues for $i$ amount to:

$$
T_{2}^{i}=\tau \delta T C_{2}^{i}+\tau(1-\delta) T C_{2}^{j}
$$

which by using (12) can be expressed as: 


$$
T_{2}^{i}=\tau(1-\pi)\left(1+h\left(g^{i}\right)\right) S^{i}+\tau \pi\left(1+h\left(g^{j}\right)\right) S^{j}+\tau w(1-S)
$$

where:

$$
\pi=\frac{\bar{\mu}_{2}-\delta\left[\bar{\mu}_{2}-\underline{\mu}_{2}\right]}{\bar{\mu}_{2}-\underline{\mu}_{2}} \in[0,1]
$$

is a measure of the fiscal externality or "leakage" of public investment due to graduate mobility and fiscal equalization: Region $i$ ends up with only the fraction $1-\pi$ of the tax payments of its former students.

Third, not all talented children born in $i$ will necessarily study at the local university. They do so only if the individual period 1 mobility cost exceeds the earnings differential between regions:

$$
\mu_{1} \geq(1-\tau) w\left[h\left(g^{j}\right)-h\left(g^{i}\right)\right] /(1+r),
$$

where (14) suppresses solutions boundary to simplify the exposition by presuming that both $g^{i}$ and $g^{j}$ exceed $\bar{e}_{0}(0)$. Using the properties of the distribution of $\mu_{1}$ gives the number of children born and studying in $i$ :

$$
S_{i}^{i}=\frac{S}{\bar{\mu}_{1}-\underline{\mu}_{1}} \cdot\left[\bar{\mu}_{1}-(1-\tau) w \frac{h\left(g^{j}\right)-h\left(g^{i}\right)}{1+r}\right]
$$

where the subscript refers to the region of origin and the superscript to the region of study. Accordingly, the number of students in $i$ originating from $j$ is $1-S_{j}^{i}$, such that the total number of students in $i$ becomes:

$$
S^{i}=S\left[1+2 \frac{(1-\tau) w}{\bar{\mu}_{1}-\underline{\mu}_{1}} \frac{h\left(g^{i}\right)-h\left(g^{j}\right)}{1+r}\right] .
$$

Obviously, educational quality attracts students:

$$
\frac{\partial S^{i}}{\partial g^{i}}=2 S \frac{(1-\tau) w}{\bar{\mu}_{1}-\underline{\mu}_{1}} \frac{h^{\prime}\left(g^{i}\right)}{1+r}>0, \frac{\partial S^{j}}{\partial g^{i}}=-2 S \frac{(1-\tau) w}{\bar{\mu}_{1}-\underline{\mu}_{1}} \frac{h^{\prime}\left(g^{j}\right)}{1+r}<0 .
$$

At last, all children not attending university get the same period 1 income in both regions. Accordingly, only those with negative mobility cost move. Since the interregional net flow of non-students is zero, period 1 tax revenue is independent of the degree of educational federalism: like in period 2 , each region has $(1-S)$ non-academic resident children. 
Therefore, the problem of the parents in region $i$ is to maximize (11) with respect to $g^{i}$, subject to (13) and (15), taking $g^{j}$ as given. This gives the first order condition:

$$
\begin{aligned}
\frac{\partial b^{i}}{\partial g^{i}} & =S^{i}\left[(1-\pi) \tau w h^{\prime}\left(g^{i}\right)-(1+r)\right] \\
& +\frac{\partial S^{i}}{\partial g^{i}}\left[-g^{i}(1+r)+\tau(1-\pi)\left(1+h\left(g^{i}\right)\right) w\right]+\pi \tau\left(1+h\left(g^{j}\right)\right) w \frac{\partial S^{j}}{\partial g^{i}} \leq 0 .
\end{aligned}
$$

with equality if $g^{i} \geq \bar{e}_{0}$. The respective second order condition:

$$
\begin{aligned}
\frac{\partial^{2} b^{i}}{\partial\left(g^{i}\right)^{2}}= & S^{i}(1-\pi) \tau h^{\prime \prime}\left(g^{i}\right)+2 \frac{\partial S^{i}}{\partial g^{i}}\left[-(1+r)+\tau(1-\pi) h^{\prime}\left(g^{i}\right) w\right] \\
& +\frac{\partial^{2} S^{i}}{\partial\left(g^{i}\right)^{2}}\left[-(1+r) g^{i}+\tau(1-\pi)\left(1+h\left(g^{i}\right)\right) w\right]<0,
\end{aligned}
$$

is assumed to be fulfilled. This can be ensured by a sufficiently low sensibility of location choice with respect to quality differentials. ${ }^{11}$

According to (16) improving local educational expenditures has three effects. First, it affects the difference between marginal tax revenues and cost for all actual students. Second, it attracts additional students who generate both tax revenue and cost. And third, the reduction of students in the other region impinges on tax revenues to the extent of fiscal leakage.

We concentrate on a symmetric equilibrium where $g^{i}=g^{j}, S^{i}=S^{j}=S$, and $\frac{\partial S^{j}}{\partial g^{i}}=$ $-\frac{\partial S^{i}}{\partial g^{i}}$. Therefore, the equilibrium spending level in both regions is either $\bar{g}^{D}$ solving:

$$
\begin{aligned}
\bar{\Omega}^{D} & =\left[(1-\pi) \tau h^{\prime}\left(\bar{g}^{D}\right) w-(1+r)\right] \\
& +2 \frac{(1-\tau) w}{\bar{\mu}_{1}-\underline{\mu}_{1}} \frac{h^{\prime}\left(\bar{g}^{D}\right)}{1+r}\left[\tau(1-2 \pi)\left(1+h\left(\bar{g}^{D}\right)\right) w-\bar{g}^{D}(1+r)\right]=0,
\end{aligned}
$$

if $\bar{g}^{D} \geq \bar{e}_{0}$ or is zero otherwise.

In what follows, we assume that the equilibrium has the property $\frac{\partial^{2} \bar{\Omega}^{D}}{\partial\left(\bar{g}^{D}\right)^{2}}<0 .{ }^{12}$ Otherwise, a higher opportunity cost of higher education in form of an increased interest rate would be conducive to public spending in the absence of fiscal externalities:

$$
\left.\frac{d \bar{g}^{D}}{d r}\right|_{\pi=0}=-\frac{-1-2 \frac{(1-\tau) h^{\prime}\left(\bar{g}^{D}\right) w}{\left(\bar{\mu}_{1}-\underline{\mu}_{1}\right)(1+r)^{2}} \tau\left(1+h\left(\bar{g}^{D}\right)\right) w}{\partial^{2} \bar{\Omega}^{D} / \partial\left(\bar{g}^{D}\right)^{2}} .
$$

11 If $\bar{\mu}_{1}-\underline{\mu}_{1}$ is sufficiently high and attracting students increases $b\left(\tau(1-\pi) w\left[1+h\left(g^{i}\right) w\right]>(1+r) g^{i}\right)$, $\tau(1-\pi) h^{\prime}\left(g^{i}\right) w>1+r$ must hold due to (16), rendering all terms in (17) are negative.

12 Again, this is always the case if the increase in local enrolment due to rising quality is not too intense. 
Proposition 2. Under decentralized pure public funding, educational spending decreases in the fiscal externality for $\pi \in[0, \bar{\pi}]$. There is no regional provision of higher education if $\pi \in[\bar{\pi}, 1]$. Educational quality is higher than under centralization if $\pi<\tilde{\pi}$, with $\bar{\pi}<\tilde{\pi}<1 / 2$.

Proof. By use of the implicit function theorem:

$$
\frac{d \bar{g}^{D}}{d \pi}=-\frac{-\tau h^{\prime}\left(\bar{g}^{D}\right)-4 \tau\left(1+h\left(\bar{g}^{D}\right)\right) \frac{(1-\tau) w^{2}}{\left(\bar{\mu}_{1}-\underline{\mu}_{1}\right)(1+r)}}{\partial^{2} \Omega^{D} / \partial\left(\bar{g}^{D}\right)^{2}}<0
$$

whenever (18) characterizes the equilibrium. Moreover, all terms in (18) are negative for $\pi=1$, and hence $\bar{g}^{D}=0$. For $\pi=0$, instead, (18) becomes:

$$
\left[\tau h^{\prime}\left(g^{D}\right) w-(1+r)\right]+2 \frac{(1-\tau) w}{\left(\bar{\mu}_{1}-\underline{\mu}_{1}\right)(1+r)}\left[\tau\left(1+h\left(g^{D}\right)\right) w-g^{D}(1+r)\right]=0 .
$$

By (9), (19) can only be fulfilled for $\bar{g}^{D}>\bar{g}^{C}$. Because $\bar{g}^{D}$ is continuous in $\pi$, there must be a level $\tilde{\pi}$ for which $\bar{g}^{D}=\bar{g}^{C}$, and a threshold $\bar{\pi}$ for which the participation becomes binding, with $\tilde{\pi}<\bar{\pi}$ due to $\bar{g}^{C}>\bar{e}_{0}$. Hence, $\bar{g}^{D}$ falls to zero for $\pi>\bar{\pi}$. For $\pi=1 / 2$, the second column in (18) is negative, implying $\bar{g}^{D}<\bar{g}^{C}$ as the first row would also become negative for the level $\bar{g}^{C}$.

[Insert Figure 1 about here]

Figure 1 illustrates the proposition. While the negative relation between perceived marginal return and higher educational investment is straightforward, the relative performance of decentralization is easily explained in terms of the strategic interrelation between spending levels. From the reaction function (16):

$$
\frac{d g^{i}}{d g^{j}}=\frac{-1}{\partial^{2} b^{i} / \partial\left(g^{i}\right)^{2}}\left[\frac{\partial S^{i}}{\partial g^{i}}\left(\tau w(1-\pi) h^{\prime}\left(g^{i}\right)-(1+r)\right)+\frac{\partial S^{j}}{\partial g^{i}} \pi \tau w h^{\prime}\left(g^{j}\right)\right] .
$$

The sign of this expression equals the sign of the square bracketed term in the numerator, which captures the basic educational tradeoff faced by each region. On the one hand, it has an incentive to attract students (and later taxpayers) by providing a better quality than the competitor. This creates a strategic complementarity between local educational expenditures. On the other hand, there is also a substitutability because each region can free ride on the expenditures of the other region by relying on fiscal equalization and the immigration of some graduates. The relative importance of these effects is determined by the extent of the fiscal externality. If for example $\pi=0$, regions appropriate all later tax revenues of local students and engage in a 
fierce competition for students leading to expenditures above the centralized level. ${ }^{13}$ Algebraically, (20) is positive and strategic complementarity prevails. ${ }^{14}$ In the other polar case $\pi=1$, however, own educational investments would only benefit the other region. Therefore, an intermediate level of fiscal leakage exists for which centralization and decentralization yield identical quality.

This result puts some caution on the popular finding that decentralized education policies are inferior to centralized ones. Both Justman and Thisse (1997) and Del Rey (2001) establish a respective result based on the mobility of graduates, but neglecting any beneficial effects of attracting students to a region. In a model with student mobility only, Büttner and Schwager (2004) find educational expenditures to be strategic substitutes. However, this result hinges on the assumption that each region cares for the earnings of all its citizens wherever they reside. Obviously, this downplays the fiscal effect of graduates remaining abroad. ${ }^{15}$ Bailey et al. (2003) present some empirical evidence that competition among US state universities reduces educational spending. In a model calibrated to the US where public education can be supplemented by private purchases, Soares (2005) finds large welfare gains from shifting from community-wide to nation-wide funding.

In contrast, Gradstein and Justman (1995) have shown that decentralization raises spending levels. However, their argument is set up in terms of human capital investment of immobile residents in order to attract mobile physical capital. In our model, educational spending is used to attract students and their future tax payments. Moreover, decentralized spending is excessive in Gradstein and Justman (1995) because - in contrast to our model - centralization would be efficient.

Nevertheless, centralization leads to higher expenditures than decentralization in a number of cases, including $\pi=1 / 2$ which reflects a situation without graduate mobility $\left(\underline{\mu}_{2}=0\right)$, but full fiscal equalization $(\delta=1 / 2)$. Moreover, the fiscal externality can even preclude a decentralized supply of higher education, although centralized provision would exist $(\pi>\tilde{\pi})$.

13 With the results at hand, we can not exclude the possibility of inefficiently high provision, as the equilibrium condition $h^{\prime}\left(\bar{g}^{D}\right) w \leq(1+r) / \tau$ is not incompatible with $\bar{g}^{D}>e^{*}$. However, Proposition 4 , to be derived at a later stage, implies that decentralization leads unambiguously to underfunding. 14 The sign of (20) for $\pi=0$ follows from (16) recognizing that the per student tax revenue is positive.

15 Moreover, the opposite result obtains under that regional target function once mobility is restricted to graduates, see Justman and Thisse (2000). 


\section{Allowing for Tuition Fees}

We now consider a setting where higher education can be financed by both public and private funds. In line with recent real-world reforms, we posit that the level of tuition fees is set by the government. Since all individuals have access to the perfect capital market and educational success is certain, the well known problems of wealthbiased demand for privately funded education are absent and require no further state intervention. ${ }^{16}$

\subsection{Centralization}

Using the relation $e=g+f$, the problem of the parents is to maximize:

$$
b=\frac{1}{2 P}\left[T_{1}+\frac{T_{2}}{1+r}-2 S(e-f)\right],
$$

with respect to $e$ and $f$ subject to student participation $\left(e \geq \bar{e}_{0}(f)\right)$, tax revenues in period 2 being:

$$
T_{2}=2 \tau w[S(1+h(e))+(1-S)]
$$

Public funding results as the difference between total and private expenditures.

Proposition 3. Under centralization, the availability of tuition fees leads to a withdrawal of public funding. Tuition fees do not improve educational quality.

Proof. The first order condition of maximizing (21) with respect to $e$ is:

$$
h^{\prime}(e) w=\frac{1+r}{\tau}
$$

which is solved by $\bar{g}^{D}$. Moreover, $\bar{g}^{D}$ is feasible for $f=0$. However, for any given $e,(21)$ increases monotonously in $f$ as long as $e \geq \bar{e}_{0}(f)$. Therefore, the maximization of (21) results for $e=\bar{g}^{C}=\bar{e}_{0}\left(f^{C}\right)$ and $g^{C}=\bar{g}^{C}-f^{C}$. The proposition follows immediately from comparison with the case $f=0$.

Since the marginal return and cost of total higher education have not changed, tuition fees have no impact on the quality preferred by parents. However, the fees serve to shift the financing burden towards students as long as their participation is ensured.

16 As pointed out by Garcia-Peñalosa and Wälde (2000), the precise form of fee repayment facilities matters for student risk taking under uncertainty. See Poutvaara (2004) for an extension of the analysis of tuition fee designs to the presence of graduate mobility. 
Therefore, there is full crowding out of public funds by fees up to the point where the talented become indifferent towards educational choice as illustrated by Figure 2.

As a consequence, the model provides some support to the assertion that allowing for state regulated tuition fees is not conducive to the quality of higher education. The next section investigates to what extent this argument applies to decentralization.

[Insert Figure 2 about here]

\subsection{Decentralization}

With regional decision making, tuition fees affect the location choice of students. A talented child born in $i$ will go to university in the region of birth only if the migration cost exceeds the earnings differential net tuition cost differentials between $i$ and $j$ :

$$
\mu_{1} \geq \frac{(1-\tau) w}{1+r}\left[h\left(e^{j}\right)-h\left(e^{i}\right)\right]-\left[f^{i}-f^{j}\right] .
$$

Therefore, the total number of students in region $i$ becomes dependant on qualities and fees:

$$
\left.S^{i}=S\left[1+\frac{2}{\bar{\mu}_{1}-\underline{\mu}_{1}}\left(\frac{(1-\tau) w\left[h\left(e^{i}\right)-h\left(e^{j}\right)\right]}{1+r}+f^{j}-f^{i}\right)\right)\right],
$$

and an increase in quality increases local enrolment, whereas a higher fee is deterrent: ${ }^{17}$

$$
\frac{\partial S^{i}}{\partial e^{i}}=S \frac{(1-\tau) w}{\bar{\mu}_{1}-\underline{\mu}_{1}} \frac{h^{\prime}\left(e^{i}\right)}{1+r}>0, \frac{\partial S^{i}}{\partial f^{i}}=\frac{-S}{\bar{\mu}_{1}-\underline{\mu}_{1}}<0
$$

Under these premises, parents in each region maximize:

$$
b^{i}=\frac{1}{P}\left[T_{1}^{i}+\frac{T_{2}^{i}}{1+r}-S^{i}\left(e^{i}-f^{i}\right)\right],
$$

with respect to $e^{i}$ and $f^{i}$, considering student participation and the tax revenue:

17 These ceteris paribus effects have to be disentangled from the question how tuition fees affect enrolment if they supplement public funding. This effect amounts to:

$$
\frac{\partial S^{i}}{\partial e^{i}}+\frac{\partial S^{i}}{\partial f^{i}}=S \frac{(1-\tau) w h^{\prime}\left(e^{i}\right) /(1+r)-1}{\bar{\mu}_{1}-\underline{\mu}_{1}} \gtreqless 0 .
$$

and is positive (negative) if public funding is sufficiently low (high). 


$$
T_{2}^{i}=\tau w(1-\pi)\left(1+h\left(e^{i}\right)\right) S^{i}+\tau w \pi\left(1+h\left(e^{j}\right)\right) S^{j}+\tau w(1-S) .
$$

The resulting first order conditions are:

$$
\begin{aligned}
\frac{\partial b^{i}}{\partial e^{i}}= & S^{i}\left[(1-\pi) \tau w h^{\prime}\left(e^{i}\right)-(1+r)\right]+\frac{\partial S^{i}}{\partial e^{i}}\left[\left(f^{i}-e^{i}\right)(1+r)+\tau(1-\pi)\left(1+h\left(e^{i}\right)\right) w\right] \\
+ & \pi \tau\left(1+h\left(e^{j}\right)\right) w \frac{\partial S^{j}}{\partial e^{i}} \leq 0 \\
\frac{\partial b^{i}}{\partial f^{i}}= & (1+r) S^{i}+\frac{\partial S^{i}}{\partial f^{i}}\left[\left(f^{i}-e^{i}\right)(1+r)+\tau(1-\pi)\left(1+h\left(e^{i}\right)\right) w\right] \\
& +\pi \tau\left(1+h\left(e^{j}\right)\right) w \frac{\partial S^{j}}{\partial f^{i}} \leq 0 .
\end{aligned}
$$

The interpretation of (25) is analogous to (16). Regarding tuition fees, each region trades off the reduction in public spending with the financial consequences of deterring students to the other region.

As a consequence, the symmetric equilibrium is characterized by:

$$
\begin{aligned}
b_{e}^{i}=- & (1+r)+\tau(1-\pi) h^{\prime}(e) \\
& +2 S \frac{(1-\tau) h^{\prime}(e)}{\left(\bar{\mu}_{1}-\underline{\mu}_{1}\right)(1+r)}[(1+r)(f-e)+\tau(1-2 \pi)(1+h(e)) w] \leq 0 \\
& =1+r-2 S \frac{1}{\left(\bar{\mu}_{1}-\underline{\mu}_{1}\right)}[(f-e)(1+r)+\tau(1-2 \pi)(1+h(e)) w] \leq 0 .
\end{aligned}
$$

Under the same assumptions as with pure public funding, $b^{i}$ is concave in $e^{i}$. Moreover, $b^{i}$ is unambiguously concave in $f^{i}$. In what follows, we consider the global optimality condition $\frac{\partial_{2} b^{i}}{\partial e_{2}^{i}} \frac{\partial_{2} b^{i}}{\partial f_{2}^{i}}>\left(\frac{\partial_{2} b^{i}}{\partial e^{i} \partial f^{i}}\right)^{2}$ as fulfilled.

The following lemma provides a useful insight in terms of the characterization of the equilibrium.

Lemma. No symmetric equilibrium violates the student participation constraint.

Proof. Suppose both regions choose $e$ and $f$ such that the student participation constraint is violated. Then, each talented pays taxes in amount $\tau w(2+r) /(1+r)$ from his non-academic occupation. A unilateral move to a policy $(e, f)$ such that $e=\bar{e}_{0}(f)$ changes the regional payoff according to: $\frac{\tau(1+h(e)) w}{1+r}-e+\frac{(1-\tau)(h(e)-1) w}{1+r}-\tau w \frac{2+r}{1+r}=$ $\left(\frac{h(e)}{1+r}-1\right) w-e$. This expression is positive whenever higher education is socially 
productive: $(a h(e)-1) w>e$. Since socially productive $e$ always exist, there is no equilibrium where both regions violate the student participation constraint.

Each region has an incentive to provide some university education when all student rents are extracted by tuition fees. Hence, unlike in the pure public funding case, the nonexistence of higher education under decentralization is not an issue.

Consequently, two possibilities for a symmetric equilibrium remain: tuition fees can be either zero or positive, both with positive student demand. We label positive fees for which the student participation constraint is not binding as moderate.

Proposition 4. A symmetric equilibrium with moderate tuition fees under decentralization is characterized by:

$$
h^{\prime}\left(e^{D}\right) w=\frac{1+r}{1-\tau \pi} .
$$

The utilization of tuition fees improves higher education quality. However, total spending is inefficiently low.

Proof. (29) follows immediately from equating (27) and (28). Moreover, from (27):

$$
\frac{d e}{d f}=-\frac{2 S(1-\tau) w h^{\prime}(e)}{\left(\bar{\mu}_{1}-\underline{\mu}_{1}\right) \frac{\partial^{2} b_{e}^{i}}{\partial e^{2}}}>0
$$

Hence, total quality chosen according to (27) is the higher, the higher the fees. Underfunding follows from $h^{\prime}\left(e^{D}\right)>h^{\prime}\left(e^{*}\right)$ by comparing (29) and (3).

The positive effect of tuition fees on overall quality arises from their regional deterrence: A regional substitution of tuition fees for public funds on a one-to-one basis would provoke some talented children to move away. In order to avoid this, there is no full crowding out of public funds. As a consequence, equilibrium quality under decentralization is higher for moderate fees than if they were banned. These results notwithstanding, there is no full resolution of the underfunding problem. ${ }^{18}$

Moreover, the above finding begs the question whether tuition fees will be introduced at all. By (28), this is the case if the marginal return of increasing $f^{i}$ is positive for $f^{i}=0, e^{i}=\bar{g}^{D}$ :

18 Since total expenditures in the presence of fees are at least as high as without fees, one can conclude that decentralized pure public funding leads to underprovision as stated above. 


$$
\begin{aligned}
\left.\frac{d b_{f}^{i}}{d f}\right|_{\substack{f=0, e=\bar{g}^{D}}}=- & (1+r)+\tau(1-\pi) h^{\prime}\left(\bar{g}^{D}\right) \\
& +2 S \frac{(1-\tau) h^{\prime}\left(\bar{g}^{D}\right)}{\left(\bar{\mu}_{1}-\underline{\mu}_{1}\right)(1+r)}\left[-(1+r) \bar{g}^{D}+\tau(1-2 \pi)\left(1+h\left(\bar{g}^{D}\right)\right) w\right]>0
\end{aligned}
$$

which by using (18) is equivalent to:

$$
h^{\prime}\left(\bar{g}^{D}\right) w>\frac{1+r}{1-\tau \pi} .
$$

This condition is the more likely met, the higher the financial gains from introducing fees, that is, the lower the preexisting level of public funding and the higher the marginal productivity of given expenditures. A higher tax rate, however, has a negative impact, as it mitigates the problem of pure public underfunding and increases the marginal revenue loss due to student deterrence. Accordingly, the effect of the fiscal externality on the incentives to introduce fees is ambiguous. Here, the marginal cost of student mobility decreases in quality because tax revenues are concave in $e$. However, the wedge between efficient and pure public funding is increased.

We are now in the position to compare the performance of centralized and decentralized educational competencies. As a first result:

Proposition 5. For moderate tuition fees, decentralized education leads to higher quality than centralized education if the fiscal externality is sufficiently low.

Proof. Comparing (18) and (29) gives $e^{D} \gtrless \bar{g}^{D} \Longleftrightarrow \pi \lessgtr(1+r)(1-\tau) / \tau$.

Like under pure public funding, decentralization provides better teaching quality than centralization when the fiscal externality is sufficiently low. However, this threshold value is affected by the availability of tuition fees.

Proposition 6. When tuition fees are available, decentralization leads to higher educational expenditures than centralization for $\pi<\tilde{\tilde{\pi}}, \tilde{\pi}<\tilde{\tilde{\pi}}$.

Proof. Since fees do not decrease total spending, $e^{D}>\bar{g}^{D}$ for all $\pi<\tilde{\pi}$. For $\pi=\tilde{\pi}$, decentralization implies higher total expenditures than centralization when fees are introduced. Therefore, $\tilde{\pi}<(1+r)(1-\tau) / \tau$ must hold. Moreover, (31) is fulfilled for $\left.\tilde{\pi}: h^{\prime}\left(\bar{g}^{D}\right)=(1+r) / \tau>(1+r) /(1-\tau \tilde{\pi})\right)$. By continuity, there must be $\pi>\tilde{\pi}$ for which $e^{D}>\bar{g}^{D}$.

Regions face an incentive to introduce fees for the level of the fiscal externality equal- 
izing centralized and decentralized expenditures under pure public funding. Then, decentralization must provide a higher quality, because total expenditures increase in $f$. Figure 3 illustrates.

This finding has consequences for the proper allocation of educational responsibilities.

Corollary. With pure public education, decentralization leads to higher welfare than centralization for $\pi<\tilde{\pi}$. When tuition fees are allowed, decentralization delivers higher welfare for $\pi<\tilde{\tilde{\pi}}$.

Proof. follows from Proposition 6 and the fact that decentralization never leads to excessive funding.

Hence, educational federalism matters for the quality of universities, with the availability of fees strengthening the case for decentralization. For any fiscal externality $\pi \in[\tilde{\pi}, \tilde{\tilde{\pi}}]$, the availability of tuition fees makes the welfare superior system the centralized rather than the decentralized one.

[Insert Figure 3 about here]

\section{Conclusion}

This paper has shown that the quality effects of state regulated tuition fees depend crucially on the degree of educational decentralization. We show that such fees do not improve total expenditures when educational decisions are centralized, a result in line with recent experiences in Australia and the UK. However, federal competition precludes a similar development under decentralized decision-making and tuition fees contribute to the quality of higher education. Therefore, the availability of fees can make a shift from a centralized to a decentralized system of university finance worthwhile. Unfortunately, reliable empirical evidence on the quality implications of tuition fees in countries with decentralized higher education is currently not available.

As it stands, the model has used a number of simplifying assumptions. First, we have developed our arguments in the context of a two period setup rather than in a model of overlapping generations. The latter would complicate the analysis but leave the general results unaffected. The most serious modification would be the consideration of parental mobility, responding to benefit differentials across regions. While the concomitant increase in the number of benefit recipients would diminish the gains from quality enhancements, the higher caution of decentralized decision makers in substi- 
tuting tuition fees for public funding would not be affected.

Second, we have concentrated on symmetric equilibria under decentralization. Certainly, the possibility of regional disparities, possibly produced by differences in regional endowments, requires further investigation. However, it should be stressed that heterogeneity affects both decentralized and centralized decisions (Besley and Coate, 2003).

Third, we have assumed that all students have the same ability to benefit from higher education. With heterogenous abilities, tuition fees would affect the size and the productivity of the student body, as the marginal student would refrain from attending university. To the extent that this reduces tax revenues, parents would want to compensate for this by providing a higher quality. Hence, crowding out of public funding under centralization would be less severe than the above analysis suggests. However, as parents face an analogous incentive also at the regional level, no qualitative difference to the above findings can be expected.

And fourth, we have not addressed the issue of regional tax competition. A number of studies has shown that the strive for mobile graduates puts a downward pressure on regional taxes, see e.g. Anderson and Konrad (2003). As a consequence, incentives to provide pure public education under decentralization are reduced. However, the effects in the presence of tuition fees are not straightforward. First, a lower tax rate slackens the student participation constraint for given expenditures and fees. Second, tax competition can be mitigated as fees make up for a financing source independent of future student residence. And third, the fundamental difference in incentives to substitute public funds for tuition fees derived above still applies. In general, we expect that the overall result depends on the division of educational and tax responsibilities between local and federal governments, an issue that we leave for future research just like the related question whether results could be improved by university autonomy. 


\section{References}

Andersson, F. and K. Konrad (2003), Human Capital Investment and Globalization in Extortionary States, Journal of Public Economics 87, 1539-1555.

Bailey, M.A., M.C. Rom and M.M. Taylor (2003), State Competition in Higher Education: A Race to the Top, A Race to the Bottom?, Economics of Governance 5, 53-75.

Barr, N. (2004), The Economics of the Welfare State, 4th Edition, Oxford University Press.

Barr, N. and I. Crawford (2005), Financing Higher Education. Answers from the UK, Routledge.

Besley, T. and S. Coate (2003), Centralized versus decentralized Provision of Local Public Goods: A Political Economy Approach, Journal of Public Economics 87, 26112637.

Bevia, C. and I. Iturbe-Ormaexte (2002), Redistribution and Subsidies to Higher Education, Scandinavian Journal of Economics 104, 321-240.

Büttner, T. and R. Schwager (2004), Regionale Verteilungseffekte der Hochschulfinanzierung und ihrer Konsequenzen, in: Franz, W., H.J. Ramser and M. Stadler: Bildung, Mohr Siebeck.

Creedy, J. and P. Francois (1990), Financing Higher Education and Majority Voting, Journal of Public Economics 24, 181-200.

De Fraja, G. (2001), Education Policies: Equity, Efficiency and Voting Equilibrium, Economic Journal 111, C104-C119.

Del Rey, E. (2001), Economic Integration and Public Provision of Education, Empirica 28, 203-218.

European Commission (2005), Mobilising the Brainpower of Europe: Enabling Universities to Make their Full Contribution to the Lisbon Strategy, Communication from the Commission 152, download: www.europa.eu.int/comm/education/policies/2010/doc/ comuniv2005_en.pdf

Fernandez, R. and R. Rogerson (1996), Income Distribution, Communities, and the Quality of Public Education, Quarterly Journal of Economics 111, 135-164.

García-Peñalosa, C. and K. Wälde (2000), Efficiency and Equity Effects of Subsidies 
to Higher Education, Oxford Economic Papers 52, 702-722.

Gradstein, M. and M. Justman (1995), Competitive Investment in Higher Education: The Need for Policy Coordination, Economics Letters 47, 393-400.

HRK (German Rectors' Conference) (2005), HRK-President Welcomes Constitutional Ruling and Demands University Autonomy Regarding Tuition Fees, download www.hrk. de/eng/presse/95_1599.php

Justman, M. and J.-F. Thisse (1997), Implications of the Mobility of Skilled Labor for Local Public Funding of Higher Education, Economics Letters 55, 409-412.

Justman, M. and J.-F. Thisse (2000), Local Public Funding of Higher Education when Skilled Labor is Imperfectly Mobile, International Tax and Public Finance 7, 247-258.

Keen, M. and M. Marchand (1997), Fiscal Competition and the Pattern of Public Spending, Journal of Public Economics 66, 33-53.

Kupferschmidt, F. and B.U. Wigger (2005), Öffentliche versus private Finanzierung der Hochschulbildung: Effizienz- und Verteilungsaspekte, Perspektiven der Wirtschaftspolitik, forthcoming.

Poutvaara, P. (2004), Educating Europe: Should Public Education be Financed with Graduate Taxes or Income-contingent Loans? CESifo Economic Studies 50, 663-684.

Poutvaara, P. and V. Kanniainen (2000), Why Invest in Your neighbor? Social Contract on Educational Investment, International Tax and Public Finance 7, 547-562.

Soares, J. (2005), Public Education Reform: Community or National Funding of Education? Journal of Monetary Economics 52, 669-697.

Somanathan, R. (1998), School Heterogeneity, Human Capital Accumulation, and Standards, Journal of Public Economics 67, 369-397.

Wigger, B. and R.K. v. Weizsäcker (2001), Risk, Resources and Education: Public versus Private Financing of Higher Education, IMF Staff Papers 48, 547-560.

Wildasin, D.E. (2000), Labor-Market Integration, Investment in Risky Human Capital, and Fiscal Competition, American Economic Review 90, 73-95. 


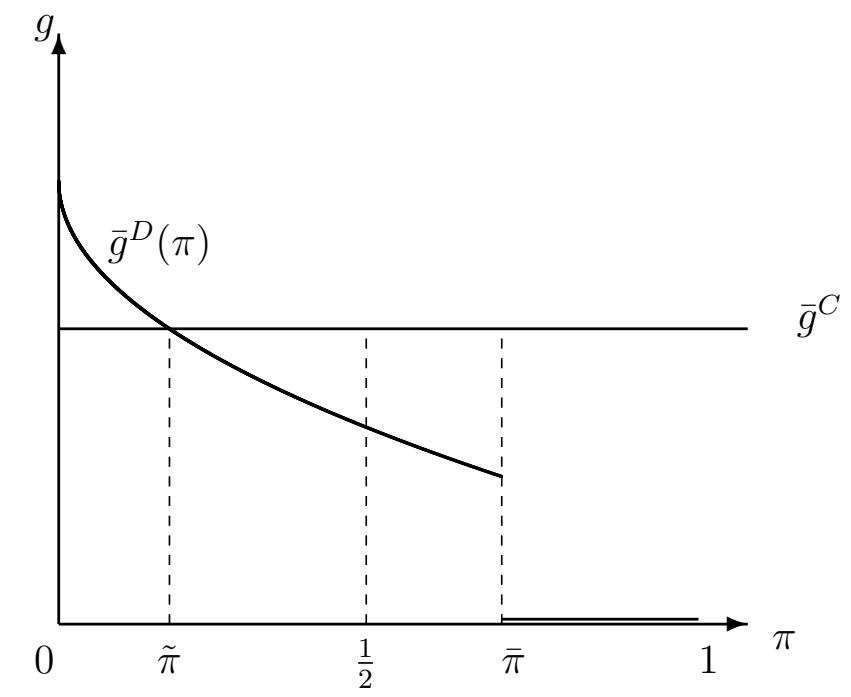

Figure 1: Pure public funding 


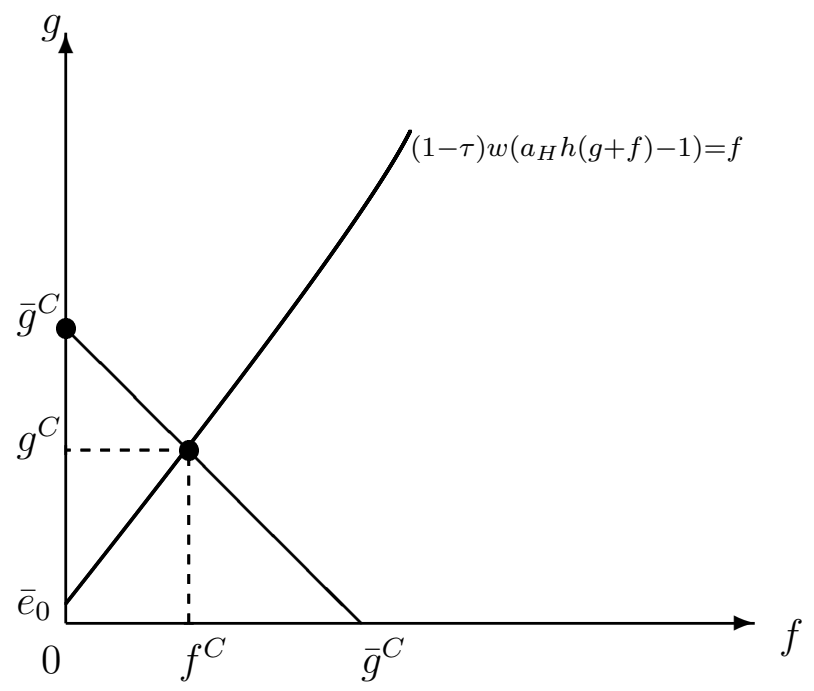

Figure 2: The level of centralized public funding with and without tuition fees

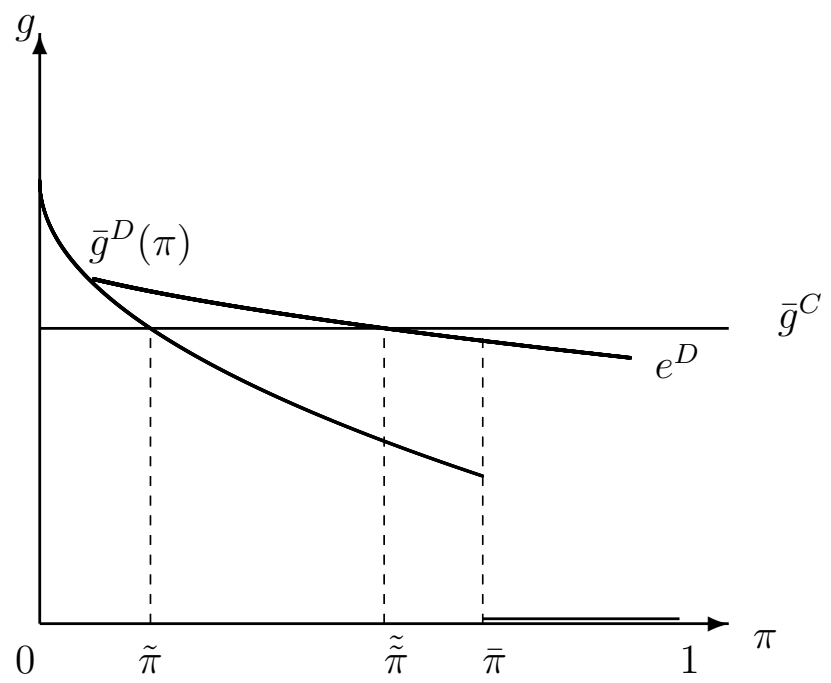

Figure 3: Centralized vs. decentralized education with tuition fees 